\title{
Fatty Embolism (Pathogenesis, Treatment)
}

\section{Bocharov SN*, Mankov AV, Bocharova YuS, Morikov DD, Sorokina LV and Golub IE}

Department of Anesthesiology - Resuscitation, Irkutsk State Medical University of the Ministry of Health of the Russian Federation, Irkutsk, Russia

*Corresponding Author: Bocharov SN, Department of Anesthesiology Resuscitation, Irkutsk State Medical University of the Ministry of Health of the Russian Federation, Irkutsk, Russia.

DOI: 10.31080/ASOR.2022.05.0427
Received: January 24, 2022

Published: February 21, 2022

(C) All rights are reserved by Bocharov SN., et al.

\begin{abstract}
Despite the historical antiquity of fat embolism syndrome, its treatment remains a subject of de-bate and one of the significant medical problems, since none of the theories has a key link in its development, by influencing which one can effectively prevent and treat ittreated. In this regard, the aim of the work was to develop the pathogenesis of fat embolism syndrome and determine an effective, pathogenetically based, method of its treatment.

Material and Methods: In the main 85 patients who were performed: determination of the presence of fatty globules at various stages of underwent total hip arthroplasty (TETS), the following treatment; dynamics of lipid metabolism markers; cholesterol level; dynamics of bio-chemical criteria that made it possible to formulate the pathogenesis of fat embolism and determine the key link in its development. In 194 patients, studies were performed to determine the most effective method of prevention and treatment with various drug substrates.

Outcomes: In 79\% of cases, during the performance of TETS operations, patients develop fatty hyperglobulemia. Based on the results of the studies performed, a scheme of pathogenesis of the syndrome of fat embolism/hyperglobulemia was formulated, the key link of which is the insufficiency of a hepatocyte (liver failure), acting on which it is possible to successfully stop its development. Medicinal substrates of prevention and treatment were: the traditionally prescribed solution of Essentiale $\mathrm{H}$ (Lipostabil); $5 \%$ alcohol solution in $5 \%$ glucose solution and pathogenetically based hepato protector "Hepasol A".

Conclusion: According to the results of the studies performed, it was established that the key link in the formation of fatty globulemia is the functional insufficiency of the hepatocyte. The use of a 5\% solution of ethyl alcohol diluted in a 5\% glucose solution is al-most identical in clinical effectiveness to the amino acid hepato protector, but with strict adherence to the technology of its use (calculated dosage of $0.5 \mathrm{~g} / \mathrm{kg}$ of body weight is administered during the day)! Traditionally prescribed and used solution "Essentiale $\mathrm{H}^{\prime \prime}$ has neither clinical nor laboratory significance.
\end{abstract}

Keywords: Pathogenesis; Fat Embolism; Lipid Metabolism; Total Endoprosthetics

\section{Abbreviation}

LDL: Low Density Lipoproteins; VLDL: Low-density Lipoproteins; HDL: High-Density Lipoproteins; ARDS: Acute Respiratory Distress Syndrome; SPON: Multi-organ Failure Syndrome; SJE: Fat Embolism Syndrome; TETS: Total Hip Replacement; TG: Triglycerides; XM: Chylomicrons

\section{Introduction}

More than 150 years have passed since the first mention of fat embolism syndrome (SJE). Initially, Zenker in 1862 discovered fat droplets in the capillaries of the lungs of a miner, and then Wagner - in 1865, on the basis of 48 autopsies, revealed a fat 
embolism in traumatic bone marrow damage. Park in 1884 published an overview material almost reflecting the modern idea of fat embolism: the causes of which are any damage to bones, soft tissues rich in fat, surgical operations on the musculoskeletal system of the body. Symptoms: weakness, pallor of the skin, turning into cyanosis; agitation, turning into a coma. This condition is more often not diagnosed, and the treatment consisted in rest, alcohol intake!!!, digitalis, the use of ether and the supply of oxygen $[1,3,12,14,16]$.

Interest in fat embolism syndrome has experienced repeated ups and downs. Despite the fact that at present a huge amount of knowledge in this area has been accumulated, the problem has not been finally solved. As before, the recovery of a patient with fat embolism syndrome most often depends on the reserve capabilities of the patient's body and, to a lesser extent, on the efforts of medical personnel. Of course, the low effectiveness of medical care in the development of fat embolism syndrome is due to the lack of a unified concept of the pathogenesis of this complication. There are many theories of pathogenesis proposed: from mechanical to complex cascading theory, but none of the existing ones denotes a key link in the pathological process, acting on which it would be possible to effectively block its development.

Mechanical theory suggests that fatty globules that enter the venous system through the venous sinuses damaged by injury cause multisystem dysfunction due to physical vascular obstruction $[5,10,13]$. Fat cells have pro-inflammatory and prothrombotic potential, cause rapid platelet aggregation and stimulate the formation of fibrin, eventually settling in the circulatory bed of the lungs [10]. Obstruction of the pulmonary capillaries causes hemorrhages, interstitial edema, alveoli collabation, reactive hypoxemic vasoconstriction [10]. Massive fat embolism leads to microvascular obstruction and shock [5]. On the other hand, biochemical theory considers severe vasculitis and its secondary histotoxic effects in SFE due to excessive mobilization of free fatty acids $[5,12,13]$. Bone marrow fat is degraded by tissue lipases, which leads to an increase in the concentration of glycerol and toxic free fatty acids [3]. Damage to the endothelium of the pulmonary capillaries triggers a cascade of anti-inflammatory cytokines and leads to the development of acute respiratory acids. distress syndrome (ARDS) [5]. The biochemical theory is supported by an increase in plasma phospholipase A2, pro-inflammatory cytokines and free radicals in patients with SJE $[4,9,15]$. In most cases, SJE occurs a combination of mechanical and biochemical processes. Manifestations of SJE are caused by embolism in both the venous and arterial bed. A technical rash appears due to post obstructive hemorrhages at the capillary level, but also may be a consequence of a systemic inflammatory response and a prothrombotic condition. Symptoms of disorders in the central nervous system (CNS) range from local deficiency to encephalopathy, which also confirms the multifactorial pathogenesis of SJE $[4,10,11]$. According to the results of experimental studies, we have identified a decrease in cholesterol and HDL, which indirectly indicates the early development of functional liver failure, since more than $80 \%$ of cholesterol is synthesized by a hepatocyte. In addition, they are non-specific antioxidants, and a decrease in their concentration indicates a decrease in the antioxidant potential of plasma and the activation of free radical oxidation processes. A simultaneous increase in the level of chylomicronemia (CM) also indicates inhibition of lipolytic activity of the hepatocyte [1-3,16].

This was the motive for an in-depth study of the features of lipid metabolism and the pathogenesis of fatty hyperglobulemia ( $\mathrm{HH})$.

The aim of the work was to develop the pathogenesis of fat embolism syndrome and determine an effective pathogenetically based method of its treatment.

\section{Research Material and Methods}

The study included 85 patients with various pathologies of the hip joints who underwent operations «Total Hip Replacement» (TETS). Drug prophylaxis of fat embolism was carried out by intravenous administration of a solution of essentiale $\mathrm{H} 20.0 \mathrm{ml}$ before surgery, during the treatment of the bone marrow canal and in the early postoperative period of $40.0 \mathrm{ml}$ in several doses. For a blood test for the presence of fatty globulemia, blood samples were taken from the central vein at the stages: before the operation, during the treatment of the bone marrow canal, at the end of the operation, in the first, second, third day after the operation. Detection and counting of fat globules were carried out using light microscopy of a smear of venous blood plasma stained by Sudan III $[11,12]$. The result was considered positive when globules larger than $6 \mu \mathrm{m}$ were detected in a smear. Lipid fractions (VLDL, LDL, HDL) was determined by electrophoresis on gel plates using diagnostic kits from Cormay (Poland). As a means of measurement, 
the semi-automatic biochemical analyzer «Humalyzer 2000» (Germany), the densitometer «Sebia» of the company «Cormay» (Poland) were used. The level of cholesterol was assessed using the diagnostic kit of the company Vital (St. Petersburg) by the enzymatic method (norm: 3.62-8.03 mmol/l). The concentration of triglycerides was determined by the enzymatic colorimetric method using the human $\mathrm{GmbH}$ test system (Germany) (norm: 0.6-2.2 mmol/l). The concentration of apolipoprotein A (norm: 94-178 mg/dL) and apolipoprotein B (norm: 63-133 mg/dL) was determined by immunoturbidimetric method using test kits from Byo Systems (COD 31095, 31098) (Spain). The activity of plasma lipoprotein lipase was investigated using the enzymatic kinetic method with use of test kits of the company «Biocon» (COD 9162)
(Germany) (norm: $190 \mathrm{IU} / \mathrm{l}$ ). The results of the studies performed are subjected to statistical processing using the Statistica program [17].

\section{Research Results and Discussion}

It is established that in $79 \%$ of cases during the operation of total hip arthroplasty, patients develop fatty hyperglobulemia. In the first postoperative day, the number of cases of globulemia is halved. On the second day, the probability of its development decreases, but still remains significant. And only by the third postoperative days the chance of developing fatty globulemia is significantly reduced compared to the intraoperative stage (Table 1).

\begin{tabular}{|c|c|c|c|c|c|}
\hline $\begin{array}{l}\text { Frequency of detection of fatty } \\
\text { globulemia in the intraoperative } \\
\text { period total hip replacement Ostaver }\end{array}$ & $\begin{array}{c}\text { Before } \\
\text { surgery }\end{array}$ & After surgery & $1^{\text {st }}$ day & $2^{\text {nd }}$ day & 3 days \\
\hline Probability & 0 & 0.79 & 0.35 & 0.16 & 0.04 \\
\hline Chance & 0.0 & 3.76 & 0.54 & 0.2 & 0.04 \\
\hline
\end{tabular}

Table 1

In the study of lipid metabolism, a significant decrease in cholesterol levels immediately after surgery was revealed, which persisted in the first postoperative day, with a simultaneous increase in the concentration of triglycerides (Table 2).

\begin{tabular}{|c|c|c|c|c|}
\hline \multicolumn{5}{|c|}{$\begin{array}{l}\text { Changes in lipid metabolism in fatty globulemia in the } \\
\text { perioperative period of total hip replacement (Friedman } \\
\text { ANOVA), } n=85\end{array}$} \\
\hline Index & $\begin{array}{c}\text { Before } \\
\text { surgery }\end{array}$ & $\begin{array}{c}\text { After } \\
\text { surgery }\end{array}$ & $1^{\text {st }}$ day & $\mathrm{P}$ \\
\hline $\begin{array}{l}\text { Cholesterol } \\
\text { (mmol/L) }\end{array}$ & $\begin{array}{c}5.3 \\
(3.7 ; 6.2)\end{array}$ & $\begin{array}{c}3.5 \\
(3.3 ; 4.1)^{*}\end{array}$ & $\begin{array}{c}3 . \\
(2.9 ; 3.1)^{*}\end{array}$ & 0 \\
\hline $\begin{array}{l}\text { Triglycerides } \\
\text { (mmol/L) }\end{array}$ & $\begin{array}{c}1.7 \\
(0.9 ; 2.2) \\
\end{array}$ & $\begin{array}{c}2.4 \\
(1.8 ; 2.7)^{*}\end{array}$ & $\begin{array}{c}2.3 \\
(1.3 ; 2.7)^{*}\end{array}$ & 0 \\
\hline $\begin{array}{l}\text { Lipase (mg/ } \\
\text { dL) }\end{array}$ & $\begin{array}{c}202 \\
(194 ; 213)\end{array}$ & $\begin{array}{c}207 \\
(164 ; 214)\end{array}$ & $\begin{array}{c}215 \\
(218 ; 215)\end{array}$ & 0.49 \\
\hline $\begin{array}{l}\text { Apo A (mg/ } \\
\text { dL) }\end{array}$ & $\begin{array}{c}21 \\
(191 ; 214)\end{array}$ & $\begin{array}{c}208 \\
(168 ; 216)\end{array}$ & $\begin{array}{c}215 \\
(213 ; 216)\end{array}$ & 0.56 \\
\hline
\end{tabular}

Table 2

Note: * ${ }^{*}<0.05$ (Wilcoxon criterion with Bonferroni correction).
Attention is also drawn to a significant decrease in the concentration of apoprotein-B immediately after the operation, which persisted in the first day after the operation. Significant changes were also detected in the ratios of plasma lipoproteins (Table 3).

The level of chylomicronemia was significantly elevated after surgery and remained so in the first postoperative day. The level of VLDL was also elevated, while there was a decrease in HDL, the level of which, despite the increase by the first days, remained significantly below the baseline level.

The study of lipid metabolism against the background of hyperglobulemia revealed significant violations of it. An increase in the level of TG of the blood is associated not only with the flow of extravascular fat into the blood, but also with an increased energy deficit as a result of surgical intervention. Hypertriglyceridemia reflects the activation of the processes of free radical oxidation. 


\begin{tabular}{|c|c|c|c|c|}
\hline \multicolumn{5}{|c|}{$\begin{array}{l}\text { Changes in lipid metabolism in fatty globulemia in the perioperative period total hip replacement } \\
\text { (Friedman ANOVA), } \mathrm{n}=85\end{array}$} \\
\hline Index & Before surgery & After surgery & 1st day & $\mathrm{P}$ \\
\hline HM/Chylomicronemia & $0(0 ; 0)$ & $1.7(0 ; 7.35)^{*}$ & $0(0 ; 3.6)^{*}$ & 0.004 \\
\hline лПОНП/VLDL & $17.9(10.1 ; 21.9)$ & $36.6(21.3 ; 46.8)^{*}$ & $34.2(17.3 ; 48.9)^{*}$ & 0.01 \\
\hline ЛПНП/LDL & $42.7(42.5 ; 62.7)$ & $56(41.5 ; 57.2)$ & $45.8(43.4 ; 48.7)$ & 0.8 \\
\hline ЛПвП/HDL & $37.4(22.4 ; 37.9)$ & $12.7(8.3 ; 23.7)^{*}$ & $23.5(11.4 ; 29.7)^{*}$ & 0.001 \\
\hline
\end{tabular}

Table 3: Resource requirements by component.

Note: ${ }^{*}-\mathrm{p}<0.05$ (Wilcoxon criterion with Bonferroni correction).

A decrease in the concentration of cholesterol indicates an acute development of functional insufficiency of the hepatocyte, which is confirmed by a violation in the ratio of LP fractions: a pronounced decrease in HDL and an increase in VLDL. At the same time, the constant amount of LDL in the blood against the background of an increase in VLDL indicates that their synthesis in the blood plasma is reduced due to its deficiency. It is known that hepatocytes instantly respond to an increase in the concentration of TG in the blood by synthesizing apoprotein-B. The time required for its synthesis is 14 minutes. A sharp decrease in this substrate against the background of fatty hyperglobulemia indicates not only a deficiency in consumption, but also about the decrease in its formation in hepatocytes.

Thus, the results of the studies confirmed the patterns of changes in lipid metabolism during hip replacement, the cause of which is the functional insufficiency of the hepatocyte and made it possible to formulate their own conceptual scheme for the formation of the syndrome of fatty hyperglobulemia/embolism, illustrated in figure 1.

The formation of fat embolism syndrome in accordance with the presented scheme can be formulated as follows. The spread of fat with blood flow after entering the vascular bed leads to embolization of the vessels of the lungs and organs of the large circle of blood circulation of varying degrees. We believe that emboli penetrate into the vessels of the small and large circle at the same time. Confirmation of the simultaneous penetration of fatty globules into the vessels of the small and large circle of blood circulation is the detection of them in the blood taken from the subclavian and peripheral veins during the treatment of the bone marrow canal during hip arthroplasty. Embolization of the vessels of the lungs and other organs leads to a violation of microcirculation, hypoxia with the launch of processes leading through metabolic disorders to the development of multiple organ failure syndrome (SPON). First of all, the liver and lungs are affected with the development of their functional insufficiency. The protective mechanism at this stage is the activation of lipoand deretic function of the body. The most important role in this process belongs to the lungs and liver. Lipoideretic function is to activate various groups of lipases, phagocytic activity, which, in the absence of a blockade of provoking factors, can take on a pathological character and lead to the formation of a vicious circle when, as a result of emulsification of the received fat there is an increased consumption of protein substrates with their depletion. This leads to a violation of the systemic metabolism of fat, a violation of the emulsion stability of plasma lipids and the accumulation of toxic products of impaired lipid metabolism. The result of these processes is the intravascular formation of fatty globules, their circulation in the blood and further embolization of the vessels of the small and large circle of blood circulation.

Thus, the outcome of the path of formation of the syndrome of fat embolism is the development of functional insufficiency of the hepatocyte, which is a key link.

The presented conceptual scheme for the development of fat embolism syndrome does not claim to be final, however, it allows us to identify a key link, acting on which it is possible to effectively solve the problem of prevention and treatment of fat embolism. This key link is the functional insufficiency of the hepatocyte!

Guided by the above scheme of the pathogenesis of the syndrome of fat embolism, we substantiated and used specific therapeutic medications to stop this syndrome. 


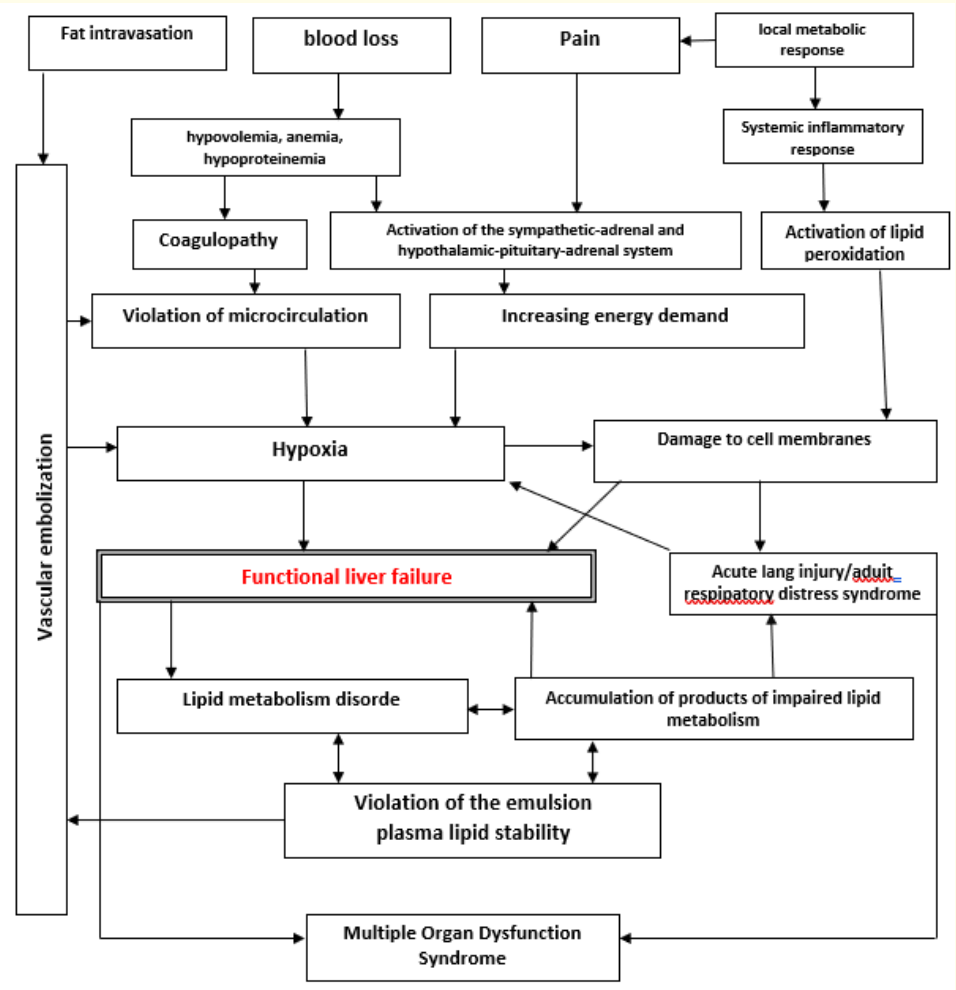

Figure 1: Pathogenetic scheme of development of fat embolism syndrome.

Specific prevention consists in the use of medications that promote emulsification, metabolism, and removal of fatty globules from the bloodstream. Preventive measures were aimed at ensuring the functional stability of the hepatocyte.Aboutthe beginning of 2000, essentiale-H (lipostabil) was considered to be practically the only drug with similar properties. This drug, due to the high concentration of phospholipids, is, in fact, an excellent emulsifier. When injected into the vascular bed, phospholipids, due to the peculiarities of the chemical structure, are built into the surface layer of lipoproteins. When injected into the vascular bed, phospholipids, due to the peculiarities of the chemical structure, are built into the surface layer of lipoproteins. high density. However, an increase in the level of HDL always leads to a decrease in the activity of lipoprotein lipase, which adversely affects the exchange of low-density lipoproteins and the utilization of fat globules. In addition, the lipid-lowering effect of essentiale $\mathrm{H}$ (lipostabile) is manifested only with its very long use, at least 6 months! $[3,10,14,16]$.
In the last twenty years, publications have appeared indicating the effectiveness of the use of Perftoran for the prevention and treatment of fat embolism associated with proxanol, which is part of its composition and provides a reduction in the size of fat globules. In addition, its ability to bind lipids, which form the basis of fatty globules, has been proven. This allows us to attribute it to specific means of prevention and treatment of fat embolism. It is used for prophylaxis at a dose of $4-8 \mathrm{ml} / \mathrm{kg}$ of weight with an interval of $1-4$ days $[8,16,18]$.

The first mention of the use of ethyl alcohol falls on 1884 and is associated with the name Park,then the use of this substrate was returned many times: in 1933 it was again proposed by Hermann, and in 1955 by Johnson M. J proposed to use it in the form of a 5\% solution of alcohol in a $5 \%$ glucose solution for the emulsification of fats. The recommended daily prophylactic dose was $0.5 \mathrm{~g}$ of ethyl alcohol per $\mathrm{kg}$ of body weight in a solution of $5 \%$ glucose, and the therapeutic dose is doubled. There is another scheme for 
the prophylactic and therapeutic use of ethyl alcohol: 1-2 g/ kg body weight per day with a rate of its administration of $0.1 \mathrm{~g} / \mathrm{kg} / \mathrm{h}$. $[6,7,14,16]$.

According to the pathogenesis of the syndrome of fat embolism/ hyperglikemia since 2005 , for the purpose of specific prevention and treatment, we have used amino acid hepatoprotectors: «Hepasol A»; «Gepasol - neo»; «Aminosteryl - gepa»; «Aminoplasm mal-hepa», which are solutions for parenteral use, containingLarginine, L-aspartic, L-malic acid in high concentrations. The main indications for their use were:

- Normalization of metabolic processes of hepatocyte;

- $\quad$ Elimination of the manifestation of functional liver failure;

- Increased antioxidant potential;

- $\quad$ Limitation of lipid peroxidation processes;

- $\quad$ Reduction of energy deficit;

- $\quad$ Decreased activity of tissue lipolysis.

According to the results of experimental - clinical studies of the effectiveness of drug prevention and treatment of fat embolism, used on the basis and conceptual scheme of development of this syndrome, it was found that the most effective drug for the prevention and treatment of fat embolism are amino acid hepatoprotectors $[1-3,16]$.

The use of essentiale solution (lipostabil) did not provide either clinical or laboratory significance!!!!, which is reflected below in the illustrated tables 4,5 of the studies conducted.

The risk of developing fatty globulemia syndrome in hip arthroplasty was investigated in three representative groups of patients. The first group included 70 patients who, during the operation and in the postoperative period, received the drug «Hepasol A» for the prevention of fatty globulemia, the second group consisted of 39 people who at the research stages were injected with a $5 \%$ solution of ethyl alcohol in a $5 \%$ glucose solution, and the third group - 85 patients received a solution of essential $\mathrm{H}$.

\begin{tabular}{|l|c|c|c|c|}
\hline Group & $\begin{array}{c}\text { Total } \\
\text { number of } \\
\text { patients }\end{array}$ & $\begin{array}{c}\text { Fat } \\
\text { globulemia }\end{array}$ & $\begin{array}{c}\text { 95\% } \\
\text { DEE }\end{array}$ & $\begin{array}{c}\text { Increase } \\
\text { Risk, \% }\end{array}$ \\
\hline Gepasol A & 70 & 38 & - & - \\
\hline $\begin{array}{l}5 \% \text { p-p } \\
\text { ethyl } \\
\text { alcohol }\end{array}$ & 39 & 26 & $6-32$ & 13 \\
\hline Essentiale H & 85 & 67 & $10-39$ & $25^{*}$ \\
\hline
\end{tabular}

Table 4: The frequency of development of fatty globulemia at the intraoperative stage.

* - p $<0.05$ ( $\chi 2$ with Yates correction).

\begin{tabular}{|l|c|c|c|c|}
\hline Group & $\begin{array}{c}\text { Total } \\
\text { number of } \\
\text { patients }\end{array}$ & $\begin{array}{c}\text { Fat } \\
\text { globulemia }\end{array}$ & $\begin{array}{c}\mathbf{9 5 \%} \\
\text { DEE }\end{array}$ & $\begin{array}{c}\text { Increase } \\
\text { Risk, \% }\end{array}$ \\
\hline Gepasol A & 70 & 11 & - & - \\
\hline $\begin{array}{l}5 \% \text { ethyl } \\
\text { alcohol } \\
\text { solution }\end{array}$ & 39 & 14 & $3-38$ & $20^{*}$ \\
\hline $\begin{array}{l}\text { Essentiale } \\
\text { H }\end{array}$ & 85 & 30 & $7-33$ & $20^{*}$ \\
\hline
\end{tabular}

Table 5: The frequency of development of fatty globulemia in the postoperative period.

* $-\mathrm{p}<0.05$ ( $\chi 2$ with Yates correction).

For the study of the presence of fatty globulemia, blood was taken from the central vein at the following stages: intraoperative - before surgery, during the treatment of the bone marrow canal, at the end of the operation, and postoperative - in the first, second, third day after the operation. Detection and counting of fat globules was carried out using light microscopy of a smear of native venous blood plasma stained by Sudan III.

As a result of the studies performed, it was established that the intraoperative use of Hepasol A reduces the risk of developing fatty globulemia compared to the use of essential $\mathrm{H}$ by $25 \%$ and by $13 \%$ compared to a $5 \%$ solution of ethyl alcohol (Table 4 ). And, in turn, a 5\% solution of ethyl alcohol and essential $\mathrm{H}$ are significantly inferior to Hepasol A in terms of effectiveness in preventing fatty globulemia in the early postoperative period (Table 5).

Thus, in operations of total hip arthroplasty, a significantly more pronounced prophylactic (anti globulemic) effect was revealed 
when using Hepasol A. Intravenous infusion of this drug during surgery and the early postoperative period significantly reduced the absolute and relative risk of developing fatty globulemia syndrome in comparison with the Essentiale H. Hepasol - A solution used during the operation provided a reduction in the risk of developing fatty globulemia after surgery without its re-administration, which allows us to talk about its prolonged preventive effect.

Traditionally recommended and used for the prevention and treatment of fat embolism, the drug «Essentiale -H» neither laboratory nor clinically has shown its effectiveness.

\section{Conclusion}

Based on the experimental and clinical studies performed, a new conceptual scheme for the formation of fatty embolism/ hyperglobulemia is proposed, in which, unlike the existing ones, the key link in its development is determined - functional insufficiency of the hepatocyte. This made it possible to pathogenetically substantiate and evaluate the effectiveness of the use of the amino acid hepatoprotector «Hepasol A» for the prevention and treatment of fat embolism syndrome/hyperglobulemia.

A significant result is the establishment of the inexpediency of using the traditionally used emulsifier «Essentiale H» (lipostabil). At the same time, the high efficiency of amino acid hepatoprotectors was confirmed, in particular «Hepasol A», the infusion of which begins on the operating table, before the skin incision, the entire period of the operation continues, the rate of administration is 80100 drops/minute. According to indications, its introduction can be repeated under laboratory quantitative and qualitative control of the presence of fatty globules.

\section{Findings}

- The key link in the pathogenesis of fat embolism is liver failure.

- An absolutely effective way to prevent and treat functional insufficiency of hepatocyte is intravenous administration of amino acid hepatoprotectors (Gapasol - A).

- The use of the traditional «Essentiale $\mathrm{H}$ » has neither clinical nor laboratory significance.

\section{Bibliography}

1. Bocharov SN., et al. "Prevention and treatment of experimental fat globulinemia”. In: Proceedings of IX Russian National Congress “Man and his Health”. Saint Petersburg (2004): 18-19.
2. Bocharov SN., et al. "Method of prevention of fat embolism in perioperative period: Patent 2326676 of the Russian Federation". 17 (2008): 1.

3. Bocharov SN., et al. "Experimental study of efficacy of the prophylaxis and treatment of fat embolism syndrome". Abstract submission of $17^{\text {th }}$ annual congress of European Society of Intensive Care Medicine. Berlin (2004): 104.

4. Han YT., et al. "Clinical features and neuroimaging findings in patients with cerebral fat embolism". Chinese Medical Journal (Engl.) 129.7 (2016): 874-876.

5. Husebye EE., et al. "Bone marrow fat in the circulation: clinical entities and pathophysiological mechanisms". Injury 37.4 (2006): 8-18.

6. Jenkins K., et al. "Fat embolism syndrome and alective knee arthroplasty”. Canadian Journal of Anaesthesia 49 (2002): 19-24.

7. Johnson MJ., et al. "Fat embolism syndrome". Orthopedics 19.1 (1996): 41-49.

8. Ivanitsky GR., et al. "Blood changer "Perftoran"”. West. RAN 67.11 998-1013.

9. Kao SJ., et al. "Clinical and pathological features of fat embolism with acute respiratory distress syndrome". Clinical Science (Lond.) 113 (2007): 279-285.

10. Kosova E., et al. "Fat embolism syndrome". Circulation 131.3 (2015): 317-320.

11. Kornilov NV., et al. "Diagnostics of fat globulinemia in traumas and surgery of bones: methodical guidelines". Saint Petersburg (2000): 24 .

12. Kornilov NV and Kustov VM. "Fat embolism". Saint Petersburg: Morsar AV 2 (001): 287.

13. Lin KY., et al. "Favorable outcome of cerebral fat embolism syndrome with a Glasgow coma scale of 3: a case report and review of the literature". Indian Journal of Surgery 77.1 (2015): 46-48.

14. Mironov NP. "Modern approaches to the prevention and intensive care of fat embolism". Klin West 1 (1997): 48-51.

15. Prakash S., et al. "Role of interleukin-6 as an early marker of fat embolism syndrome: a clinical study". Clinical Orthopaedics and Related Research 471 (2013): 2340-2346. 
16. Plakhotina EN and Bocharov S.N. "Fat embolism". Novosibirsk: Nauka (2009): 150.

17. Rebrova OYu. "Statistical analysis of medical data. Use of the application program package STATISTICA". Moscow: Media Sfera, (2003): 312.

18. Vorobyov SI., et al. "On the issue of perfluorocarbon emulsifier". Perfluoroorganic compounds in biological medicine Pushchino 8 (1997): 143-147.

\section{Assets from publication with us}

- Prompt Acknowledgement after receiving the article

- Thorough Double blinded peer review

- Rapid Publication

- Issue of Publication Certificate

- High visibility of your Published work

Website: www.actascientific.com/

Submit Article: www.actascientific.com/submission.php

Email us: editor@actascientific.com

Contact us: +919182824667 